*Doutorando em Direito Processual Civil pela Pontifícia Universidade Católica de São Paulo E-mail: marcaonassar@yahoo.com.br

**Doutora em Direito do Estado pela Pontifícia Universidade Católica de São Paulo Professora do Mestrado em Direitos Humanos da Universidade Federal de Mato Grosso do Sul

E-mail: limaribas@uol.com.br

\section{REVISÃO JUDICIAL DE POLÍTICAS PÚBLICAS E (I)LEGITIMIDADE DEMOCRÁTICA: A CONTRIBUIÇÃO DE TÉCNICAS PROCESSUAIS DELIBERATIVAS}

\author{
JUDICIAL REVIEW OF PUBLIC POLICIES AND \\ DEMOCRATIC LEGITIMACY: THE CONTRIBUTION \\ OF DELIBERATIVE PROCEDURAL TECHNIQUES
}

\section{Marcos Nassar* Lídia Maria Ribas**}

Como citar: NASSAR, Marcos; RIBAS, Lídia Maria. Revisão judicial de políticas públicas e (i)legitimidade democrática: a contribuição de técnicas processuais deliberativas. Scientia luris, Londrina, v. 25 , n. 3, p. 159-175, nov. 2021. DOI: 10.5433/21788189.2021v25n3p159. ISSN: 2178-8189.

Resumo: $\mathrm{O}$ artigo objetiva, para além de identificar as fontes normativas legitimadoras do sistema de justiça - cujos membros não são escolhidos e controlados por meio do voto - em sua atuação revisora e amiúde modificadora de políticas públicas elaboradas e levadas a efeito por representantes democraticamente eleitos pelo povo, sobretudo verificar a viabilidade da adoção de mecanismos de incremento da legitimidade democrática de tal atuação. Utiliza-se o método hipotético-dedutivo, a partir de pesquisa bibliográfica e jurisprudencial. Parte-se, como pressuposto, da justiciabilidade dos direitos prestacionais, inclusive dos decorrentes de normas principiológicas, cuja efetividade frequentemente demanda a implementação adequada de políticas públicas. Busca-se então demonstrar que a alteração de política pública como forma de tutela de tais direitos, ainda que em caráter excepcional e com grande complexidade na prática, pode apresentar-se como único meio de proteção do direito. Por fim, apresentam-se reflexões sobre o déficit de legitimidade democrática sufragista de que padece o sistema de justiça para a aludida forma de tutela, bem como possíveis mecanismos de compensação desse déficit por meio da qualificação da atividade deliberativa do órgão jurisdicional.

Palavras-chave: Direitos prestacionais. Políticas implementadoras. Alteração judicial, Democracia. Deliberação.

Abstract: The paper aims to identify the legitimate normative 
sources of the justice system (whose members are not chosen and controlled by voting) in its reviewing and often modifying public policies elaborated and carried out by representatives democratically elected by the people, as well as and primarily to verify the feasibility of adopting mechanisms to increase democratic legitimacy in such action. The hypothetical-deductive method is used, based on bibliographic and jurisprudential research. It starts with, as an assumption, the justiciability of social-economic rights, including those resulting from principles, whose effectiveness often demands the proper implementation of public policies. The aim is to demonstrate that the change in public policy as a form of protection of such rights, even though it has an exceptional character and proves to be quite complex in practice, can present itself as the only means of protecting the right. Finally, reflections are presented on the deficit of suffragist democratic legitimacy suffered by the justice system for the aforementioned form of judicial protection, as well as possible mechanisms to compensate for this deficit through the qualification of the deliberative activity of the judicial branch.

Keywords: Social-economic rights. Policies. Judicial review. Democracy. Deliberation. 


\section{INTRODUÇÃO}

Aborda-se neste artigo a questão da legitimidade democrática do sistema de justiça, cujos membros não são escolhidos e controlados por meio do voto popular, para a realização de alterações em políticas públicas elaboradas e levadas a efeito por representantes democraticamente eleitos. Intenta-se analisar o emprego de mecanismos de incremento da legitimidade democrática dessa atividade revisora, tomando-se por empréstimo técnicas de deliberação pensadas primordialmente para o exercício da jurisdição constitucional pelas cortes constitucionais e supremas cortes.

O estudo parte do método hipotético-dedutivo e vale-se de pesquisa bibliográfica e da jurisprudência dos tribunais de superposição. Sua oportunidade decorre da notória e crescente judicialização de políticas públicas no Brasil, que já assumiu contornos de litigância massificada (como, por exemplo, no campo da saúde pública). As discussões sobre o tema centram-se mais acentuadamente em questões relacionadas à escassez de recursos, falta de previsão orçamentária e possibilidade de isso ser alegado com sucesso pelo Poder Público contra o não atendimento a prestação contida no chamado mínimo existencial. Neste trabalho, diferentemente, o foco está na própria legitimidade - nomeadamente sob o aspecto democrático - do sistema de justiça para tratar dessas questões e de outras relacionadas.

Para tanto, parte-se de análise marcadamente normativa quanto à possibilidade de tutela jurisdicional em favor de direitos prestacionais, oriundos de regras ou princípios, inclusive mediante, quando necessário, alteração na política pública destinada a dar concretude ao direito judicialmente reconhecido. Em seguida, foca-se o déficit de legitimidade democrática sufragista de que padece o sistema de justiça para a aludida forma de tutela, bem como possíveis mecanismos de compensação desse déficit, a partir da noção de deliberação peculiar ao desempenho da jurisdição constitucional.

\section{EXIGIBILIDADE DOS DIREITOS FUNDAMENTAIS PRESTACIONAIS}

Na presente seção, busca-se assentar como premissa para o restante do texto a exigibilidade em juízo dos direitos fundamentais de segunda geração ${ }^{1}$, isto é, dos direitos econômicos, sociais e culturais, cujo objeto consiste numa conduta positiva estatal.

\subsection{DIREITOS PRESTACIONAIS COMO VERDADEIROS DIREITOS SUBJETIVOS}

Para Pontes de Miranda (1995, p. 23), "direito subjetivo é atribuição de um bem da vida,

\footnotetext{
1 A despeito de vários autores adotarem a designação "dimensões" de direitos, prefere-se a terminologia mais antiga e bastante difundida: "gerações" de direitos. Não se desconhece a principal crítica que se faz ao termo "geração", que passa a ideia de sucessão, no sentido de que uma geração morre e outra nasce, ao passo que, com os direitos fundamentais, não há sucessão, mas sobreposição e complementaridade. No entanto, apesar dessa crítica, o uso da palavra "geração" bem expressa a historicidade do surgimento dos direitos fundamentais e, de resto, parece ínfimo o risco hoje em dia de o uso do termo levar ao equívoco de que teria havido uma "sucessão" de direitos.
} 
quando a lei o garante. O que o caracteriza é a subjetividade combinada com a incidência concreta da lei”. Trata-se da vantagem de determinado sujeito (titular), em relação a outro sujeito - que tem o dever correspondente -, gerada como efeito de um fato jurídico (MIRANDA, 1998). Fato jurídico, por sua vez, explica Miranda $(1995 ; 1998)$ é um fato ou um conjunto de fatos descrito na norma jurídica, que, uma vez realizado no mundo natural, recebe a incidência normativa, passando a produzir efeitos jurídicos previstos na norma, entre os quais se situam os direitos subjetivos.

Dado direito subjetivo pode ou não estar dotado de pretensão de direito material, que é a exigibilidade da prestação objeto do direito. Ela diz respeito à possibilidade de exigir-se do obrigado a satisfação do direito subjetivo. Um direito de crédito sujeito a termo inicial, por exemplo, até o vencimento da dívida, é direito subjetivo ainda não munido de pretensão: ao credor ainda não é dado exigir a prestação. Nas palavras de Pontes de Miranda, "pretensão é a posição subjetiva de poder exigir de outrem alguma prestação positiva ou negativa" (1998, p. 68). A ela corresponde a obrigação, que é o "dever premível do destinatário". Seu exercício (exigência de satisfação do direito), para ter êxito, depende da prestação voluntária do obrigado. Exercida a pretensão de direito material com recusa do obrigado em satisfazê-la, surge em favor do titular do direito a ação de direito material, que é o "exigir + agir" para a satisfação do direito, mesmo contra vontade do obrigado (MIRANDA, 1998, p. 64). A ação de direito material é hoje exercida fundamentalmente pelo Estado por entremeio da "ação" processual, com a qual se exige e se age no sentido de fazer atuar a jurisdição, a cuja prestação está o Estado obrigado. ${ }^{2}$

Em termos mais simplificados, pode-se dizer apenas que a um direito subjetivo sempre corresponde um dever, ambos regidos por uma norma de conduta (BOBBIO, 2004). Violado o direito, é devido remédio jurisdicional adequado.

Essa estrutura faz-se presente em relação aos direitos de segunda geração. O direito social é a atribuição de dado bem da vida - com a imputação do correlato dever -, nascida como efeito de um fato jurídico, sobre o qual incidiu a norma jurídica que garante a atribuição.

Quanto ao aspecto normativo, é de ver que tanto regras quanto princípios formulam-se por meio das expressões deônticas básicas do dever, da permissão e da proibição. Um dos mais difundidos critérios de diferenciação entre essas espécies normativas é apresentado por Robert Alexy (2008, p. 90-91): “princípios são normas que ordenam que algo seja realizado na maior medida possível dentro das possibilidades jurídicas e fáticas existentes", ou seja, são mandamentos de otimização, que podem ser satisfeitos em graus variados - as possibilidades jurídicas referemse aos princípios e regras colidentes no caso concreto -, ao passo que "as regras são normas que são sempre ou satisfeitas ou não satisfeitas", pois contêm determinações a serem satisfeitas tal qual a norma expressa. Ademais, princípios "não contêm um mandamento definitivo, mas apenas prima facie", ao passo que "regras são, se não houver o estabelecimento de alguma exceção, razões definitivas" (ALEXY, 2008, p. 104, 106). Em correlação com essa última distinção, Alexy também diferencia direitos prima facie e direitos definitivos, explicando que a tutela jurisdicional se refere apenas a esses últimos, mesmo que decorram de princípios - nesse caso, a decorrência é indireta,

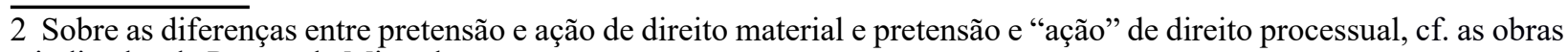
indicadas de Pontes de Miranda. 
pois o direito definitivo nasce da regra definida a partir da relação de preferência estabelecida num caso concreto de colisão.

Virgílio Afonso da Silva (2011), em relação ao suporte fático das normas de direitos fundamentais, esclarece que, de regras decorrem direitos e deveres definitivos, enquanto de princípios emanam direitos e deveres prima facie. O princípio garante e impõe algo prima facie e apenas em cada caso será possível definir o que é garantido e imposto definitivamente. ${ }^{3}$

Vê-se, pois, que, mesmo de princípios, sem suporte fático preciso e tampouco efeitos jurídicos perfeitamente pré-delimitados, podem surgir autênticos direitos subjetivos prestacionais, com pretensão e, em caso de violação, ação de direito material, muito embora a análise desse tipo de caso concreto possa mostrar-se muito mais complexa em comparação ao ordinário silogismo referente à incidência de uma regra (com suporte fático e efeitos jurídicos bem definidos). ${ }^{4}$

\subsection{RAZÕES PARA A MENOR EFETIVIDADE DOS DIREITOS PRESTACIONAIS, EM COMPARAÇÃo COM AS LIBERDADES NEGATIVAS}

O grande problema no campo dos direitos fundamentais já há bastante tempo não é mais principalmente de justificação filosófica, mas político-jurídico e prático, quanto a medidas de efetiva proteção (BOBBIO, 2004). Esse problema é ainda mais marcante quanto aos direitos prestacionais. Por isso, quanto a estes, questiona Bobbio (2004): sua previsão encontra-se em normas meramente "programáticas"? Tais normas ordenam, proíbem ou permitem num futuro indefinido? Trata-se de "direitos" cuja proteção, pela exigibilidade do correspectivo dever ou obrigação, é adiada indefinidamente? ${ }^{5}$

Para tentar elucidar a questão, importa mencionar a crítica tecida por Virgílio Afonso da Silva (2011) à conhecida classificação de José Afonso da Silva das normas constitucionais quanto à sua eficácia jurídica, encarada apenas a partir do texto constitucional. Virgílio afirma que toda e qualquer norma constitucional de direitos fundamentais pode sofrer restrições por norma infraconstitucional - o que infirma a distinção entre normas de eficácia plena e contida -, ao passo que pode (e, às vezes, deve) ser regulamentada - o que refuta e torna sem sentido a distinção entre

3 Tratando de direitos fundamentais nascidos a partir de princípios, Virgílio Afonso da Silva afasta a concepção de suporte fático restrito, pela qual haveria definição a priori do âmbito de proteção da norma, com a exclusão de dadas condutas, estados e posições jurídicas. Ele adota a noção de suporte fático amplo (sem exclusões a priori): sua definição exata dá-se apenas diante das peculiaridades do caso e das demais normas incidentes. Assim, em se tratando da incidência de um princípio constitucional, "um direito social também deve ser realizado na maior medida possível, diante das condições fáticas e jurídicas presentes" (SILVA, 2011, p. 205).

4 A intenção aqui, como pressuposto para o restante do artigo, é somente afirmar a possibilidade de exigir-se judicialmente a satisfação de direitos prestacionais decorrentes de normas principiológicas. Refoge aos objetivos do artigo enfrentar os exageros verificados, inclusive no âmbito do controle jurisdicional de políticas públicas, em razão de alegada aplicação de princípios, sem que exista, porém, parâmetro normativo de controle minimamente claro, isto é, com densidade suficiente a superar a presunção de legitimidade dos atos do Legislativo e do Executivo, cujos membros foram eleitos para tomar decisões políticas em nome do povo, nos limites constitucionais. A análise desses exageros, que dão azo ao chamado decisionismo judicial - por meio do qual o julgador substitui, de forma ilegítima, deliberações de representantes do povo, eleitos, por suas próprias preferências pessoais, travestidas de supostos princípios jurídicos -, demandaria pelo menos outra pesquisa inteira.

5 Também para Bobbio (1999), princípios são espécies de normas jurídicas. 
normas de eficácia plena e limitada. Além disso, restrição e regulamentação são atividades com diferenças tênues e muitas vezes se confundem na prática.

Em geral, a eficácia plena é associada aos direitos de primeira geração, enquanto a limitada é relacionada aos direitos de segunda geração, os prestacionais. Para Virgílio Afonso da Silva (2011), essas associações derivam menos do texto normativo do que de opções político-ideológicas. Em realidade, a efetivação por meio de políticas públicas é que parece ser determinante para a eficácia da norma. Eficácia aqui num conceito que vai além da aptidão para produção de efeitos jurídicos ante a presença dos respectivos pressupostos normativos, para abarcar também a ideia de efetividade, de efetivação prática dos direitos.

A diferença central entre os direitos prestacionais, tradicionalmente vinculados à eficácia limitada, e os direitos de liberdade, associados em geral à eficácia plena, está na existência de condições (institucionais, legais, materiais etc.) de produção de efeitos desses últimos e na inexistência de tais condições em relação àqueles. ${ }^{6}$

\section{INAFASTABILIDAdE DA REVISÃo DE POLÍTICAS PÚbLICAS PELO SISTEMA DE JUSTIÇA NA ATUAL ORDEM CONSTITUCIONAL}

Firmadas em linhas gerais, consoante se buscou fazer na seção precedente, as razões pelas quais a violação a direitos subjetivos prestacionais deve render ensejo a tutela jurisdicional, pretende-se expor, na seção ora iniciada, a possibilidade de essa tutela efetivar-se, quando necessário, por intermédio de alteração da política pública relativa ao direito reconhecido.

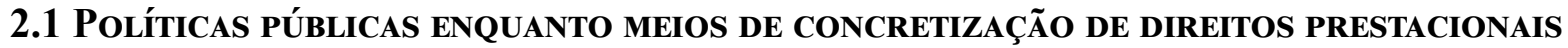

Políticas públicas são instrumentos estatais para o alcance de objetivos socialmente relevantes, inclusive a implementação de direitos econômicos, sociais e culturais (como, por exemplo, o direito à saúde e à educação). Cuida-se de "uma atividade, isto é, um conjunto organizado de normas e atos tendentes à realização de um objetivo determinado" (COMPARATO, 1998, p. 45). Confira-se a respeito a lição de Maria Paula Dallari Bucci (2001, p. 13):

Pode-se partir de uma definição provisória de políticas públicas como programas de ação governamental voltados à concretização de direitos. [...] Há uma estreita relação entre os temas das políticas públicas e dos direitos humanos. Pois uma das características do movimento de ampliação do conteúdo jurídico da dignidade humana é a multiplicação das demandas por direitos, demandas diversificadas e pulverizadas na titularidade de indivíduos.

6 A efetividade dos direitos sociais depende de custos maiores que a dos direitos de liberdade, em especial porque cada direito social (à saúde, à educação, à moradia etc.) requer investimentos específicos, ao passo que boa parte dos custos das liberdades públicas é aproveitado de maneira global por todas elas (legislação, organização judiciária etc.) (SILVA, 2011). 
Em texto posterior, a autora apresentou esta definição: "políticas públicas são programas de ação governamental visando a coordenar os meios à disposição do Estado e as atividades privadas, para a realização de objetivos socialmente relevantes e politicamente determinados" (2006, p. 241).

$\mathrm{Na}$ Constituição de 1988, previram-se vários direitos prestacionais a serem realizados por meio de políticas públicas, em linha com os fundamentos e objetivos da República, previstos nos arts. $1^{\circ} \mathrm{e}$ $3^{\circ}$. Essas previsões devem servir de norte para a definição das despesas e prioridades na elaboração do orçamente público (RIBEIRO, 2011; RAMASCO; BLANCHET, 2017), o que conduz à questão sobre o respectivo controle, como exposto a seguir.

\subsection{CONTROLE JURISDiCIONAL DE POLÍticas PÚBLICAS}

As Constituições dos Estados sociais passaram a estabelecer os fins coletivos a serem perseguidos e programas de ação a serem implementados. Com isso, colocou-se como consequência previsível a questão da judicialização das políticas públicas (COMPARATO, 1998). Hoje, a normatividade das aludidas previsões constitucionais é amplamente reconhecida, com o que se abre a possibilidade de exigência de seu cumprimento em juízo. Isso decorre, ainda, na linha que se vem expondo, do seguinte: como os direitos prestacionais são passíveis de tutela jurisdicional, logo, as políticas públicas voltadas à sua implementação podem ser submetidas a controle jurisdicional. Cuida-se de consequência lógica desse modelo de concretização estatal de direitos.

Além disso, a possibilidade desse controle judicial é também decorrência da adoção pelo Brasil do presidencialismo. O modelo presidencialista de inspiração norte-americana originou-se do objetivo de contenção do poder, para evitar abusos. Daí a penetração encontrada nos Estados Unidos pela teoria de Montesquieu, de dispersão do poder e checks and balances, com controles mútuos entre os diversos entes e órgãos estatais investidos de poder (tripartição dos poderes, unidades federativas parciais e ente central etc.). O controle de constitucionalidade, nesse sistema de governo, é o recurso mais expressivo do Judiciário, determinante para que se lhe confira a estatura de poder estatal. Nos Estados Unidos, apesar de esse modelo ter sido adotado já na Constituição em 1787, o controle de constitucionalidade só passou do campo da potencialidade para o da realidade em 1803, com o julgamento pela Suprema Corte, presidida pelo juiz Marshall, do famoso caso Marbury versus Madison, e foi consolidando-se paralelamente ao fortalecimento do sistema de justiça. Por isso, não obstante a influência de Montesquieu para a dispersão do poder que marcou a Constituição norte-americana, sua ideia de juiz como mera "boca da lei” não prosperou no curso da história do país (SADEK, 2013a; SADEK, 2013b). ${ }^{7}$

De outro lado, no Judiciário brasileiro, por muito tempo, a autocontenção foi a marca

7 No sistema parlamentarista, apesar de sua origem também remontar ao liberalismo político - ou seja, à ideia de Estado de Direito e contenção do poder -, a ênfase não está na dispersão do poder, mas sim na transferência deste das mãos do monarca para o parlamento, de sorte que a centralidade da figura do parlamento enfraquece a indicada função revisora do Judiciário (SADEK, 2013a; SADEK, 2013b). 
na seara do controle de políticas públicas. Isso, porém, começou a mudar com a Lei da Ação Popular (Lei 4.717/65) e alterou-se profundamente com a Constituição de 1988, ante, por exemplo, o estabelecimento de objetivos fundamentais da República e do princípio da moralidade administrativa como parâmetro de controle (v. arts. 5, LXXIII, e 37) (GRINOVER, 2013).

Atualmente, a judicialização de políticas públicas é fenômeno bem conhecido no Brasil e considerado inerente à ordem constitucional vigente, garantidora de inúmeros direitos prestacionais. Mais uma razão disso está em que, quanto maior o detalhamento do texto constitucional e do rol de direitos fundamentais, notadamente os sociais, maior é o espaço para a atuação judicial no controle de políticas públicas (SADEK, 2013 ${ }^{\mathrm{a}}$; SADEK, 2013b). São esclarecedoras, quanto ao ponto, as lições de Maria Paula Dallari Bucci (2001, p. 10):

O problema da justiciabilidade dos direitos sociais se alarga muito, passando a abarcar todo o caminho de efetivação de um direito, desde o seu nascimento, quando é previsto na norma, até a sua emancipação, quando é encartado em determinado programa de ação de um governo e passa a integrar medidas de execução. Em outras palavras, a exigibilidade de um direito aparece nas várias fases de organização temporal da política pública, desde o estabelecimento da agenda (agenda setting), a formulação de alternativas, a decisão, a implementação da política, a execução até a fase final, da avaliação.

Assim, a constatação de que a Constituição de 1988 adotou o sistema de governo presidencialista e encerra texto bastante pormenorizado, com amplo leque de direitos prestacionais (à saúde, educação, moradia etc.) e medidas de garantia de direitos - por exemplo, aplicabilidade imediata dos direitos fundamentais, inafastabilidade jurisdicional e fortalecimento do Ministério Público -, é indicativa do espaço aberto no país para o controle jurisdicional das políticas públicas (SADEK, 2013a; SADEK, 2013b).

De resto, não obstante as dificuldades práticas, o controle judicial encontra legitimidade não só em texto constitucional expresso - notadamente no art. $5^{\circ}, \mathrm{XXXV}$ (inafastabilidade jurisdicional) e $\S 1^{\circ}$ (aplicabilidade imediata das normas de direitos fundamentais ${ }^{8}$ ) -, como na própria ideia de constitucionalismo, que distingue o poder constituinte do povo, que edita a lei mais alta, e o poder ordinário das autoridades do governo e do eleitorado, de que resulta a lei comum. Numa democracia constitucional, o poder ordinário é limitado e guiado pelo poder constituinte, relação garantida pelo estabelecimento do controle de constitucionalidade. Não há, pois, supremacia parlamentar. Tampouco a corte suprema exerce o poder supremo, que é exercido pelos três poderes em sua relação constitucionalmente estabelecida e todos são responsáveis perante o povo. ${ }^{9}$ Daí resulta que o controle de constitucionalidade é antimajoritário apenas no que se refere à lei ordinária, mas não relativamente à autoridade superior do povo e à lei mais alta. Fica claro, assim, que a revisão judicial não é antidemocrática, ao menos a partir da noção de democracia constitucional (RAWLS,

8 Confira-se, a propósito, SARLET, 2008, p. 13 e 20, com referência à doutrina sobre a matéria.

9 “A constituição não é o que a Suprema Corte diz que ela é, e sim o que povo, agindo constitucionalmente por meio dos outros poderes, permitirá à Corte dizer que ela é. Uma interpretação específica da constituição pode ser imposta à Corte por emendas, ou por uma maioria ampla e estável, como ocorreu no caso do New Deal" (RAWLS, 2000, p. 288). 
2000).

Há certo tempo está sedimentado também na jurisprudência, inclusive no Supremo Tribunal Federal, que é permitido ao sistema de justiça, notadamente ao Ministério Público e ao Poder Judiciário, o controle de políticas públicas em face de situações de injustificável comportamento estatal (comissivo, omissivo ou parcialmente omissivo) quanto à efetivação de direitos sociais assegurados constitucionalmente. ${ }^{10}$ É que, apesar de competir primariamente aos Poderes Legislativo e Executivo a elaboração e execução de políticas públicas, cabe ao Ministério Público, no exercício de suas funções institucionais ${ }^{11}$, e ao Poder Judiciário, no exercício da jurisdição, promoverem o cumprimento da Constituição, na efetivação de políticas públicas por ela impostas, em casos de comportamentos estatais descumpridores, de modo irrazoável, das normas respectivas. A legitimidade, assim, para tal atuação do sistema de justiça, ainda que sob a marca da excepcionalidade, é conferida pelo próprio texto constitucional, expressão máxima do poder soberano popular (art. $1^{\circ}$, parágrafo único).

É preciso frisar, ainda, que não se cuida - nem se pode cuidar - de controle judicial do mérito administrativo propriamente dito, ou seja, a revisão judicial não pode ser motivada por razões de discricionariedade. O controle só pode desencadear-se por razões de legalidade lato sensu, ou seja, de juridicidade. Dessarte, a atuação do sistema de justiça só pode legitimamente iniciar-se em razão de (e para remediar) violação ou ameaça de violação a direito, em decorrência de abuso governamental, garantindo-se a supremacia da Constituição. ${ }^{12}$

10 Desde a conhecida decisão do Ministro Celso de Mello na ADPF n. 45 (BRASIL, 2004) - que, apesar de em sua conclusão ter apenas extinguido o processo sem exame de mérito, tornou-se precedente paradigmático quanto à possibilidade de controle jurisdicional de políticas públicas, como expõem não sem um bem fundamentado caráter crítico Diego Werneck Arguelhes e Leandro Molhano Ribeiro (2015) -, foram proferidas pelo STF, com a mesma linha argumentativa, inúmeras outras, monocráticas e colegiadas. A título ilustrativo, indiquem-se alguns acórdãos sobre: (i) implantação da Defensoria Pública no âmbito estadual: AI 598212 ED, Rel. Min. Celso de Mello, 2T, j. em 25/3/2014, DJe-077 23/4/2014; (ii) ampliação e melhoria no atendimento de gestantes em maternidades estaduais: RE 581352 AgR, Rel. Min. Celso de Mello, 2T, j. em 29/10/2013, DJe-230 21/11/2013; (iii) direito à saúde: AI 734487 AgR, Rel. Min. Ellen Gracie, 2T, j. em 3/8/2010, DJe-154 19/8/2010; (iv) segurança pública: RE 628159 AgR, Rel. Min. Rosa Weber, 1T, j. em 25/6/2013, DJe-159 14/8/2013; RE 559646 AgR, Rel. Min. Ellen Gracie, 2T, j. em 7/6/2011, DJe-120 22/6/2011; e RE 367432 AgR, Rel. Min. Eros Grau, 2T, j. em 20/4/2010, DJe086 13/5/2010; (v) gratuidade nos transportes coletivos urbanos aos maiores de 65 anos: AI 707810 AgR, Rel. Min. Rosa Weber, 1T, j. em 22/5/2012, DJe-110 5/6/2012; (vi) acesso e atendimento em creches e unidades de pré-escola para crianças: ARE 639337 AgR, Rel. Min. Celso de Mello, 2T, j. em 23/8/2011, DJe-177 14/9/2011; e RE 410715 AgR, Rel. Min. Celso de Mello, 2T, j. em 22/11/2005, DJ 3/2/2006; (vii) vaga em estabelecimento de educação infantil: RE 595595 AgR, Rel. Min. Eros Grau, 2T, j. em 28/4/2009, DJe-099 28/5/2009; e (viii) transporte de alunos da rede estadual de ensino: RE 603575 AgR, Rel. Min. Eros Grau, 2T, j. em 20/4/2010, DJe-086 13/5/2010. Cf. outros acórdãos do STF sobre a judicialização de políticas públicas: RE $788170 \mathrm{AgR}$, Rel Min. Cármen Lúcia, 2T, j. em 22/4/2014, DJe-085 6/5/2014; RE 658171 AgR, Rel. Min. Dias Toffoli, 1T, j. em 1\%/4/2014, Dje-079 25/4/2014; e RE 677524 AgR, Rel. Min. Cármen Lúcia, 1T, j. em 24/4/2012, DJe-096 16/5/2012. No mesmo sentido vem pronunciando-se o Superior Tribunal de Justiça (STJ). Também a título exemplificativo, vejam-se alguns arestos sobre: $(i)$ efetivo acesso e atendimento em creches e unidades de pré-escola: EREsp 485969/SP, Rel. Min. José Delgado, 1S, j. em 23/8/2006, DJ 11/9/2006, p. 220); (ii) fornecimento de medicamentos: AgRg no REsp 1107511/ RS, Rel. Min. Herman Benjamin, 2T, j. em 21/11/2013, DJe 6/12/2013; (iii) direitos previdenciários: REsp 1309137/ MG, Rel. Min. herman benjamin, 2T,j. em 8/5/2012, DJe 22/5/2012; e (iv) implementação do modelo de assistência à saúde do índio e instalação material de serviços de saúde à população indígena: REsp 811608/RS, Rel. Min Luiz Fux, 1T, j. em 15/5/2007, DJ 4/6/2007, p. 314.

11 Em especial: art. 127, caput, da Constituição: "defesa da ordem jurídica, do regime democrático e dos interesses sociais e individuais indisponíveis"; e art. 129, II e III, da Constituição: "zelar pelo efetivo respeito dos Poderes Públicos e dos serviços de relevância pública aos direitos assegurados nesta Constituição, promovendo as medidas necessárias a sua garantia"; e "promover o inquérito civil e a ação civil pública, para a proteção do patrimônio público e social, do meio ambiente e de outros interesses difusos e coletivos".

12 Frise-se que a apreciação desse tipo de caso não costuma ser simples. Pode suceder de a própria análise sobre a existência do direito e sua violação ser complexa, como indicado no item 1.1.Vale, portanto, reafirmar aqui a ilegitimidade do decisionismo judicial que disfarça sob a aparente aplicação de princípios de conteúdo bastante aberto (como o da dignidade humana, por exemplo) a substituição de decisões políticas amparadas pelo voto por 


\section{MECANISMOS DE ATENUAÇÃO DO DÉFICIT DE LEGITIMIDADE DEMOCRÁTICA SUFRAGISTA DO SISTEMA DE JUSTIÇA NA MODIFICAÇÃO DE POLÍTICAS PÚBLICAS}

Até este ponto, objetivou-se explanar que a legitimidade do sistema de justiça para o controle de políticas públicas - quando necessário para a proteção de direitos - é conferida diretamente pela ordem constitucional e pela noção de democracia constitucional. Nesta seção, intenta-se enfrentar a questão da falta de legitimidade democrática derivada do voto, de que padece o sistema de justiça no desempenho de tal tarefa, bem como indicar formas de incremento de legitimação democrática em favor desse tipo de atuação.

\subsection{FALTA DE LEGITIMIDADE PELO VOTO E ATIVIDADE DELIBERATIVA DO ÓRGÃo JURISDICIONAL}

Como já argumentava William Fletcher no início dos anos 80, o primeiro problema relativo à atuação do Judiciário para reestruturar políticas públicas refere-se à sua legitimidade. A atuação judicial aí finda por ter certo caráter discricionário e político, embora motivada por uma injuridicidade. Portanto, é presumivelmente ilegítima, porquanto não sofre o controle contra abusos decorrente do sufrágio popular. No entanto, essa presunção de ilegitimidade é superada se os órgãos políticos dos Poderes Legislativo e Executivo que devem ordinariamente realizar a discricionariedade política estão em falta séria e crônica quanto à realização de seus deveres constitucionais. A superação da presunção de ilegitimidade aí decorre da necessidade de preservar a Constituição, que, de outro modo, restaria violada sem que houvesse remédio algum. A legitimidade, então, emana da necessidade de proteger o direito constitucional ofendido, dada a ausência, em análise realística, de outra alternativa. Nessa situação excepcional, que deve ser objeto de ampla fundamentação, a atuação jurisdicional mostra-se necessária e legítima (FLETCHER, 1982).

Isso não significa, todavia, que as críticas levantadas contra esse controle a partir do argumento da ilegitimidade devam ser simplesmente ignoradas. O argumento da falta de legitimidade do sistema de justiça - cujos membros não ostentam representatividade oriunda do voto popular - para realizar modificações de decisões tomadas pelos representantes eleitos do povo sobre gastos públicos, os quais são realizados com recursos formados pelos tributos recolhidos do próprio povo (WALDRON, 1999), se, por um lado, não infirma o fato de a Constituição ter conferido explicitamente ao sistema de justiça a tarefa de realizar o controle, inclusive de constitucionalidade, dos atos do Poder Público, institucionalizando, assim, no país uma democracia constitucional, por outro, recomenda que a legitimidade nessas situações seja objeto de reflexão e, na medida do possível, de reforço.

Deveras, o argumento da carência de legitimidade judicial não é desprezível: os membros do sistema de justiça não são eleitos e não respondem diretamente perante os cidadãos e, ao modificar

preferências pessoais. Cf. acima nota n. 4 . 
políticas públicas, muitas vezes derrogam decisões tomadas por representantes do povo, eleitos e responsáveis perante a cidadania nas urnas. O contra-argumento de que o parâmetro para tal revisão é dado pelo texto constitucional, embora relevante, não é isento de críticas: a Constituição é redigida em boa parte numa linguagem vaga, que poucas vezes guarda referência direta com os casos julgados pelo Judiciário. Desse modo, a margem de discricionariedade interpretativa das normas constitucionais mostra-se, na prática, bastante larga. As comuns mudanças interpretativas do próprio STF acerca do que prescreve a Constituição são prova dessa discricionariedade. Portanto, tão somente afirmar que o parâmetro de controle está consubstanciado no texto constitucional não ilide cabalmente o argumento da falta de legitimidade judicial (HOGG; BUSHELL, 2014).

No que diz respeito ao controle de constitucionalidade, usualmente se afirma que a falta de legitimidade democrática direta (conferida pelo voto) dos órgãos judiciais incumbidos do controle é compensada por outras fontes de legitimidade, uma das quais é a qualidade da argumentação (MENDES, 2012; SILVA, 2013). Com efeito, como aludidos órgãos - inclusive as cortes constitucionais e supremas cortes - não sofrem o escrutínio do voto, sua legitimidade e autoridade decorrem, entre outras coisas, de sua posição de imparcialidade em relação às disputas políticas e da fundamentação de suas decisões, calcada no ordenamento jurídico, que é produzido por representantes eleitos pelo povo - o que confere à decisão judicial uma espécie de justificação democrática indireta. Essa fundamentação, na linha do pensamento de Rawls (2000), é feita a partir da ideia de razão pública. De outro lado, a fundamentação da decisão tem também uma função legitimadora não relacionada com a democracia, mas sim com propiciar previsibilidade (segurança jurídica) para planejamento de ações futuras por parte de agentes estatais e particulares (FEREJOHN; PASQUINO, 2003).

Ao tratar da deliberação como uma das fontes de legitimação do controle de constitucionalidade, a doutrina especializada costuma distingui-la em interna e externa. As práticas deliberativas internas referem-se ao esforço de persuasão e racionalidade empreendido entre os membros do colegiado incumbido de tomar a decisão. Já a deliberação externa consiste também num esforço de persuasão e racionalidade, mas desta feita voltado para fora do órgão jurisdicional, de modo que este ativamente escute e considere razões oriundas de fora (FEREJOHN; PASQUINO, 2004)

Conrado Hubner Mendes (2012) esclarece melhor essa classificação ao explicar as fases deliberativas do julgamento, às quais correspondem tarefas deliberativas específicas: à primeira fase (pré-decisional) correlaciona-se a tarefa de contestação pública; na segunda (decisional), tem lugar a interação colegiada; e a terceira (pós-decisional) refere-se à redação da decisão tomada. A segunda fase é interna. A primeira e terceira são externas, pois o órgão judicial interage com a esfera pública, esperando-se que os interlocutores sejam participantes ativos nessas fases, apresentando argumentos e submetendo a decisão final a um escrutínio rigoroso. No curso da contestação pública, na fase pré-decisional, ganham destaque a figura do amicus curiae e a possibilidade de realização de audiências públicas, para enriquecer-se a deliberação por meio da contribuição de interlocutores qualificados. 
Essas observações sobre a deliberação enquanto uma das fontes de legitimidade do controle de constitucionalidade valem em boa medida igualmente para a revisão judicial de políticas públicas. Isso porque, em primeiro lugar, a apreciação de políticas públicas em juízo pressupõe no mais das vezes a realização do controle difuso de constitucionalidade, uma vez que a Constituição da República prevê ampla gama de direitos sociais e políticas públicas em seu texto, que servem, pois, como parâmetros de controle. Além disso, as mesmas críticas dirigidas contra o controle de constitucionalidade no que se refere à falta de legitimidade democrática dos órgãos dele encarregados, cujos membros não são escrutinados pelas urnas, são de idêntica forma direcionadas ao controle judicial de políticas públicas. Em ambas as hipóteses o Poder Judiciário revê decisões políticas - ainda que por critérios jurídicos - tomadas por Poderes cuja legitimidade é extraída em grande parte do voto popular.

\subsection{TÉCNICAS PROCESSUAIS DE DELIBERAÇÃo E INCREMENTO DE LEGITIMIDADE Da REVISÃo JUDICIAL DE POLÍTICAS PÚbLICAS NO DIREITO BRASILEIRO}

À luz das considerações apresentadas na subseção anterior, é de pensar sobre mecanismos que incrementem a legitimidade da atuação do sistema de justiça na atividade revisional de políticas públicas. A preocupação com a ampliação do diálogo processual esteve desde o início presente na discussão acerca dos chamados processos estruturais, vocacionados à implementação de reformas institucionais, como se dá no caso de alterações em políticas públicas. Owen Fiss, um dos precursores do estudo do tema, já destacava a necessidade de fomentar-se o litisconsórcio ativo entre os diferentes legitimados concorrentes disjuntivos para o processo coletivo, de forma a levarem-se em consideração e contemplarem-se mais adequadamente os diferentes aspectos, perspectivas e ponderações dos interesses impulsionadores da demanda. O autor já salientava também que o juiz deve garantir e fomentar a participação de representantes dos interesses a serem impactados no processo, seja nos polos da relação processual, seja como amicus curiae (FISS, 1979).

Nesse contexto, importa salientar que, nomeadamente em processos coletivos, é possível adotar mecanismos de ampliação do contraditório ou democratização da decisão por meio da participação dos grupos envolvidos, especialistas etc., com a realização de audiências públicas e a intervenção de amici curiae, o que auxilia também no fornecimento de respaldo técnico para a tomada de decisões complexas de forma bem embasada. A pertinência e relevância do amicus curiae no processo coletivo são assim salientadas por Cassio Scarpinella Bueno (2013, p. 122). ${ }^{13}$ : “[o] contexto de análise dos institutos processuais no âmbito do 'direito processual coletivo' é mais adequado para o estudo do amicus curiae. Pelo menos para a construção da figura no direito brasileiro"

Quanto à audiência pública, afora seu estabelecimento para o processo administrativo

13 O novo CPC prevê, no art. 138, a possibilidade de participação de amicus curiae ("pessoa natural ou jurídica, órgão ou entidade especializada, com representatividade adequada"), "considerando a relevância da matéria, a especificidade do tema objeto da demanda ou a repercussão social da controvérsia". 
federal (Lei 9.784/1999), para o controle concentrado de constitucionalidade (Lei 9.868/1999 e 9.882/1999) e como instrumento de atuação do Ministério Público (Lei 8.625/93), o CPC de 2015 cuidou de prevê-la para o incidente de resolução de demandas repetitivas (art. 983, § $1^{\circ}$ ), os recursos repetitivos (art. 1.038, II) e a alteração de súmula ou tese jurídica adotada em caso repetitivo (art. $\left.927, \S 2^{\circ}\right) .{ }^{14}$ Muito embora ainda não haja previsão legal expressa e específica a respeito para o processo coletivo ou mesmo de forma ampla para qualquer processo, tudo recomenda a utilização da audiência pública em casos que requeiram a ampliação do contraditório e do acesso à justiça, seja em observância a esses princípios constitucionais, seja por aplicação analógica das reportadas previsões legais, seja também por tratar-se, pode-se dizer, de meio de prova atípico.

Ademais, para que se viabilizem a participação e a contribuição de colegitimados processuais, de especialistas na matéria debatida e das pessoas interessadas e potencialmente impactadas pela decisão a ser tomada quanto à política pública - seja diretamente, seja por meio da atuação de associações representativas de seus interesses -, é mister que se dê ampla publicidade ao caso a ser julgado. Para tanto, pode-se lançar mão das ferramentas oferecidas pela rede mundial de computadores - a cuja utilização amiúde remete o CPC de 2015 para comunicações e divulgações -, de jornais e outros meios idôneos.

Por outro lado, a argumentação minuciosa que deve suportar as conclusões alcançadas na decisão, abarcando, entre outras coisas, a complexidade dos valores envolvidos, os argumentos oferecidos pelos participantes do processo, as consequências materiais do julgamento, ou seja, a argumentação mais profunda e robusta exigível de decisão sobre políticas públicas, é na prática viável num número não muito grande de processos coletivos, cada qual sobre dada questão envolvendo política pública, a ser apreciada e decidida para todos os que se encontram na mesma situação. ${ }^{15}$ (Tais processos devem receber o tratamento prioritário requerido pela relevância social das questões a serem por meio deles resolvidas.)

É de ver, aliás, que essa fundamentação mais profunda e detalhada passou recentemente a ser exigida expressamente em lei para decisões em sede de revisão de políticas públicas. Com efeito, a LINDB, alterada pela Lei 13.655/2018, agora reclama expressamente "sejam consideradas as consequências práticas da decisão", estabelecendo que "[a] motivação demonstrará a necessidade e a adequação da medida imposta ou da invalidação de ato, contrato, ajuste, processo ou norma administrativa, inclusive em face das possíveis alternativas" (art. 20). O art. 21, caput, reforça a exigência: "[a] decisão que, nas esferas administrativa, controladora ou judicial, decretar a invalidação de ato, contrato, ajuste, processo ou norma administrativa deverá indicar de modo expresso suas consequências jurídicas e administrativas". E o parágrafo único desse último artigo é ainda mais minucioso quanto aos aspectos a serem contemplados na fundamentação da decisão que controla a validade de atos do Poder Público:

$14 \mathrm{O}$ instituto encontra também regulamentação em regimentos internos de tribunais e no âmbito dos Ministérios Públicos e do Conselho Nacional do Ministério Público.

15 Quanto à ampla eficácia subjetiva e espacial da sentença coletiva, cf. o recente julgamento do Recurso Extraordinário (RE) n. 1101937, com repercussão geral, pelo Supremo Tribunal Federal (STF), que reconheceu a inconstitucionalidade da restrição inserta no art. 16 da Lei 7.347/1985 (BRASIL, 2021). Cf. também a respeito: NASSAR; RIBAS, 2021. 
Parágrafo único. A decisão a que se refere o caput deste artigo deverá, quando for o caso, indicar as condições para que a regularização ocorra de modo proporcional e equânime e sem prejuízo aos interesses gerais, não se podendo impor aos sujeitos atingidos ônus ou perdas que, em função das peculiaridades do caso, sejam anormais ou excessivos.

O também novo art. 22 da LINDB prevê, ainda, que, “[n]a interpretação de normas sobre gestão pública, serão considerados os obstáculos e as dificuldades reais do gestor e as exigências das políticas públicas a seu cargo, sem prejuízo dos direitos dos administrados”.

Portanto, conclui-se que, mormente no âmbito do sistema processual coletivo, é jurídica e faticamente viável a adoção de técnicas em benefício da ampliação do diálogo processual e do incremento do ônus argumentativo para a tomada de decisões de reconfiguração de políticas públicas com maior índice de legitimidade democrática.

\section{CONCLUSÃO}

Buscou-se inicialmente demonstrar a exigibilidade judicial dos direitos prestacionais, enquanto verdadeiros direitos subjetivos, virtualmente dotados de pretensão e ação de direito material. Apresentaram-se, ainda, razões para a menor efetividade desses direitos, em comparação com as liberdades negativas, relacionadas à existência ou não de condições institucionais, legais, materiais etc. para sua concretização.

Na sequência, expôs-se a possibilidade de a tutela jurisdicional de tais direitos realizarse por intermédio de alteração da respectiva política pública. Nesse sentido, considerando-se as políticas públicas como meios de concretização de direitos prestacionais, demostrou-se que sua revisão jurisdicional pode ser necessária e indispensável à adequada tutela desses direitos, ainda que se trate de atuação excepcional do sistema de justiça, com feições bem mais complexas que as dos casos ordinários. Com isso, explanou-se que a legitimidade do sistema de justiça para o controle de políticas públicas é conferida diretamente pela ordem constitucional e pela noção de democracia constitucional.

Por fim, tratou-se da carência de legitimidade democrática ligada ao sufrágio no controle jurisdicional de políticas públicas. Como forma de atenuação dessa carência, indicaram-se técnicas processuais de qualificação da atividade deliberativa do órgão jurisdicional, tanto mediante a ampliação do diálogo processual - por exemplo, com a realização de audiências públicas e a admissão de amici curiae -, quanto pelo recrudescimento do ônus argumentativo necessário ao amparo de decisões alteradoras de políticas públicas. 


\section{REFERÊNCIAS}

ALEXY, Robert. Teoria dos direitos fundamentais. São Paulo: Malheiros, 2008.

ARGUELHES, Diego Werneck; RIBEIRO, Leandro Molhano. O Supremo individual: mecanismos de atuação direta dos ministros no processo político. Revista Direito, Estado e Sociedade, Rio de Janeiro, n. 46, p. 121-155, jan./jun. 2015.

BOBBIO, Norberto. Teoria do ordenamento jurídico. 10. ed. Brasília: UnB, 1999.

BOBBIO, Norberto. A era dos direitos. Rio de janeiro: Elsevier, 2004.

BRASIL. Supremo Tribunal Federal. Medida Cautelar em Arguição de Descumprimento de Preceito Fundamental 45. Arguição de descumprimento de preceito fundamental. A questão da legitimidade constitucional do controle e da intervenção do Poder Judiciário em tema de implementação de políticas públicas, quando configurada hipótese de abusividade governamental. Relator: Min. Celso de Mello, 29 de abril de 2004. DJ: Brasília, DF, 4 mai. 2004, p. 12.

BRASIL. Supremo Tribunal Federal (Tribunal Pleno). Recurso Extraordinário 1.101.937. Constitucional e processo civil. Inconstitucionalidade do art. 16 da Lei 7.347/1985, com a redação dada pela Lei 9.494/1997. Ação civil pública. Impossibilidade de restrição dos efeitos da sentença aos limites da competência territorial do órgão prolator. Repercussão geral. Relator: Min. Alexandre de Moraes, 8 de abril de 2021. DJe: Brasília, DF, 14 jun. 2021.

BUCCI, Maria Paula Dallari. Buscando um Conceito de Políticas Públicas para a Concretização dos Direitos Humanos. In: BUCCI, Maria Paula Dallari et al. Direitos humanos e políticas públicas. São Paulo, Pólis, 2001. 60p. (Cadernos Pólis, 2).

BUCCI, Maria Paula Dallari. Direito administrativo e políticas públicas. São Paulo: Saraiva, 2006.

BUENO, Cassio Scarpinella. Amicus curiae e evolução do direito processual civil brasileiro. In: MENDES, Aluisio Gonçalves de Castro; WAMBIER, Teresa Arruda Alvim (Org.). O processo em perspectiva. Jornadas Brasileiras de Direito Processual. 1 ed. São Paulo: Revista dos Tribunais, 2013, p. 105-129.

COMPARATO, Fábio Konder. Ensaio sobre o juízo de constitucionalidade de políticas públicas. Revista de Informação Legislativa, Brasília, v. 35, n. 138, p. 39-48, abr.jun. 1998. Disponível em: http://www2.senado.leg.br/bdsf/handle/id/364. Acesso em: 13 ago. 2019.

FEREJOHN, John; PASQUINO, Pasquale. Constitutional courts as deliberative institutions: towards an institutional theory of constitutional justice. In: SADURSKI, Wojciech (ed.).

Constitutional justice, east and west: democractic legitimacy and constitutional courts in postcommunist Europe in a comparative perspective. Amsterdã: Springer, 2003, p. 21-36.

FEREJOHN, John; PASQUINO, Pasquale. Constitutional adjudication: lessons from Europe. Texas Law Review, Austin, v. 82, n. 87, p. 1671-1704, jun. 2004. 
FISS, Owen. The Supreme Court 1978 term - foreword: forms of justice. Harvard Law Review, Austin, v. 93, n. 1, p. 1-58, nov. 1979. Disponível em: https://digitalcommons.law.yale. edu/fss_papers/1220/. Acesso em: 11 fev. 2020.

FLETCHER, William A. The discretionary constitution: institutional remedies and judicial legitimacy. Yale law journal, New Haven, v. 91, n. 4, p. 635-697, mar. 1982. Disponível em: http://digitalcommons.law.yale.edu/ylj/vol91/iss4/1. Acesso em: 11 fev. 2020.

GRINOVER, Ada Pellegrini. O controle jurisdicional de políticas públicas. In: GRINOVER, Ada Pellegrini; WATANABE, Kazuo (org.). O controle jurisdicional de políticas públicas. 2. ed. Rio de Janeiro: Forense, 2013, p. 125-150.

HOGG, Peter W.; BUSHELL, Allison A. El diálogo de la carta entre los tribunales y las legislaturas (o quizá la carta de derechos no sea algo tan malo después de todo). In:

GARGARELlA, Roberto (org.) Por una justicia dialógica: el poder judicial como promotor de la deliberación democrática. Buenos Aires: Siglo Veintiuno Editores, 2014. E-book.

MENDES, Conrado Hubner. Projeto de uma corte deliberativa. In: VOJVODIC, Adriana; PINTO, Henrique Motta; GORZONI, Paula; SOUZA, Rodrigo Pagani de. Jurisdição constitucional no Brasil. São Paulo: Malheiros, 2012, p. 53-74.

MIRANDA, Francisco Cavalcanti Pontes de. Comentários ao Código de Processo Civil. Atualização legislativa de Sérgio Bermudes. 4. ed. Rio de Janeiro: Forense, 1995. t. I.

MIRANDA, Francisco Cavalcanti Pontes de. Tratado das ações. Campinas: Bookseller, 19981999. t. I, VI e VII.

NASSAR, Marcos; RIBAS, Lídia Maria. A velha questão do alcance espacial dos efeitos da sentença coletiva e sua iminente solução com repercussão geral pelo STF. Revista Brasileira de Direito Processual, Belo Horizonte, ano 29, n. 113, p. 241-261, jan./mar. 2021.

RAMASCO, Thiago Werner; BLANCHET, Luiz Alberto. Políticas públicas: parâmetros objetivos para sua definição. Revista Argumentum, Marília, v. 18, n. 2, p. 347-361, mai.ago. 2017.

RAWLS, John. Liberalismo político. São Paulo: Ática, 2000.

RIBEIRO, Maria de Fátima. Efetivação de políticas públicas: uma questão orçamentária. Revista Argumentum, Marília, n. 12, pp. 77-102, 2011.

SADEK, Maria Tereza Aina. Judiciário, controle jurisdicional e políticas públicas. In: MENDES, Aluisio Gonçalves de Castro; WAMBIER, Teresa Arruda Alvim (Org.). O processo em perspectiva: jornadas brasileiras de direito processual. São Paulo: Revista dos Tribunais, 2013a, p. 305-312.

SADEK, Maria Tereza Aina. Judiciário e arena pública: um olhar a partir da ciência política. In: GRINOVER, Ada Pellegrini; WATANABE, Kazuo (Org.). O controle jurisdicional de políticas públicas. 2. ed. Rio de Janeiro: Forense, 2013b, p. 1-32. 
SARLET, Ingo Wolfgang. Os Direitos sociais como direitos fundamentais: contributo para um balanço aos vinte anos da constituição federal de 1988. 2008. Disponível em: http://www.stf.jus. br/arquivo/cms/processoAudienciaPublicaSaude/anexo/artigo_Ingo_DF_sociais_PETROPOLIS_ final_01_09_08.pdf. Acesso em: 29/4/2018.

SILVA, Virgílio Afonso da. Direitos fundamentais: conteúdo essencial, restrições e eficácia. 2. ed. São Paulo: Malheiros, 2011.

SILVA, Virgílio Afonso da. Deciding without deliberating. International Journal of Constitutional Law, Oxford, v. 11, n. 3, 2013, p. 557-584.

WALDRON, Jeremy. Law and disagreement. New York: Oxford University Press, 1999.

Como citar: NASSAR, Marcos; RIBAS, Lídia Maria. Revisão judicial de políticas públicas e (i) legitimidade democrática: a contribuição de técnicas processuais deliberativas. Scientia luris, Londrina, v. 25, n. 3, p. 159-175, nov. 2021. DOI: 10.5433/21788189.2021v25n3p159. ISSN: 21788189.

Recebido em 2021-05-29

Aprovado em 2021-10-13 